\title{
Scripting, control, and privacy in domestic smart grid technologies: insights from a Danish pilot study
}

\author{
Hansen, Meiken; Hauge, Bettina
}

Published in:

Energy Research \& Social Science

Link to article, DOI:

10.1016/j.erss.2017.01.005

Publication date:

2017

Document Version

Peer reviewed version

Link back to DTU Orbit

Citation (APA):

Hansen, M., \& Hauge, B. (2017). Scripting, control, and privacy in domestic smart grid technologies: insights from a Danish pilot study. Energy Research \& Social Science, 25, 112-123.

https://doi.org/10.1016/j.erss.2017.01.005

\section{General rights}

Copyright and moral rights for the publications made accessible in the public portal are retained by the authors and/or other copyright owners and it is a condition of accessing publications that users recognise and abide by the legal requirements associated with these rights.

- Users may download and print one copy of any publication from the public portal for the purpose of private study or research.

- You may not further distribute the material or use it for any profit-making activity or commercial gain

- You may freely distribute the URL identifying the publication in the public portal

If you believe that this document breaches copyright please contact us providing details, and we will remove access to the work immediately and investigate your claim 


\title{
Scripting, control, and privacy in domestic smart grid technologies: insights from a Danish pilot study
}

\author{
Authors: Meiken Hansen, Bettina Hauge \\ Keywords: Smart grid, Households, Control, Script
}

\begin{abstract}
Smart grid research in Denmark has increasingly turned its focus on aggregator trading flexibility achieved by remotely controlling appliances, studying the technologies involved rather than the control. This paper investigates how different types of control were envisioned and designed for a two-year smart grid trial in Denmark with 20 private households. Using the notion of script, processes of in- and de-scription were used to gain insights into perceived and enacted control. Based on empirical data from 26 interviews and three workshops, we show how the in-scription process of control can be characterized as dynamic and includes negotiations between the residents and those responsible for the project. Second, we show how users de-script control, and third, we outline the project owners' reaction to the user's de-scription of control.

The design of the remote control appears to have promoted a preference for 'passive consumers' within a smart grid. This design prompts questions about how the users in smart grid development are envisioned and configured using different ideas about control. With current development and the need for additional energy reductions, consumers who invest in photovoltaic solar cells and electric vehicles lose interest in delivering their energy to the system level.
\end{abstract}

\section{Introduction and background}

Throughout the world, electricity systems may undergo significant changes in the near future. In most countries, the reason for these changes is closely linked to environmental aspects: to increase the amount of renewable energy sources in the energy system and the energy efficiency (Fadaeenejad et al., 2014) to reduce global warming. As the renewable energy sources with the largest potential fluctuate, structural changes within the electricity system are needed. One method for implementing this change is the implementation of smart grids, which are intelligent electricity systems with a two-way flow of digital communication between a supplier and a consumer (European Commission, 2011). In the Netherlands, Norway and Switzerland, smart grids have been tested in households to gain a more controlled use of electricity (Broman et al., 2014; Verbong et al., 2013). Similar to other European countries, Denmark has developed an ambitious plan for substituting a large part of the technology in the energy system, which has led to large

Post-print version, please cite this paper as: Hansen, M., \& Hauge, B. (2017). Energy Research \& Social Science Scripting, control, and privacy in domestic smart grid technologies: Insights from a Danish pilot study. Energy Research \& Social Science, 25, 112-123. http://doi.org/10.1016/j.erss.2017.01.005 
investments in smart grid research. The Danish vision of smart grids is linked to a new aggregator role that will remotely control specific technologies within households (Schick \& Gad, 2015). Smart grids will cause changes on many levels of an electricity system according to experts in the field; however, the new energy system will depend on a consumer role that significantly differs from the current consumer role (Abi Ghanem \& Mander, 2014; Lunde, Røpke \& Heiskanen, 2015). Danish stakeholders in the energy field seem to envision (and prefer) consumers as passive participants in the energy transition, where technologies and price incentives are considered to initiate an appropriate and required system-wide behaviour (Nyborg \& Røpke, 2011). Other countries may have encouraged or planned a more active participation than the Danish smart grid strategy (Danish Government, 2013) seems to entail because smart grids need consumers as partners to consume energy when an abundance exists, as highlighted by Lunde et al. (2015). If the smart grid vision is to be realized, consumers need to act according to the system's needs and take on a different and more active role in relation to the system (Lunde et al., 2015). Other scholars connect the new role of consumers with flexible demand; thus, consumers shall become flexible by investing in 'flexible loads,' such as electric vehicles (EVs) and heat pumps (HPs). This flexibility connected with new monitoring and control tools will ensure the stability of the grid (Moura, López, Moreno \& Almeida, 2013).

Balta-Ozkan et al. (2014) identify two conflicting visions for consumers in smart grids. Either the main change that occurs is purely technological, with passive energy consumers, or the consumers take an active role in the use of technology as part of the solution by actively engaging with the processes of energy provision and consumption. Goulden et al. (2014) argue that the second vision (of energy citizens) may ensure a more effective smart grid, in which intelligence is utilized from both devices and users.

This new situation, with either passive or active consumers, entails new control situations in relation to the consumer, the aggregator and the technologies, as people's homes are changed by physical installations and interference with their everyday consumption. 'Control', however, is a complex notion. Smart grid research that refers to control seems to focus on the technologies facilitating control and how to use control for promoting either passive or active consumers rather than studying control itself. It is the aim of this paper to study control from the perspective of the smart grid designer and the resident. Still, 'control', 'control issues' and 'control situations' related to smart grids and households have different meanings: they may relate to the automation of consumption, such as when consumers are in control of the settings of their own new devices or relate to aggregators or specific parts of the system that enable a new remote control of electrical devices. Thus, households become arenas where new situations of control materialize (Wilson, 
Hargreaves \& Hauxwell-Baldwin, 2014), and the purpose of our study is to collect abundant data from studying issues of control at home.

We use the term 'issues of control' and the term 'control situations' interchangeably and refer to situations where the participants in Insero Live Lab or the project owners exercise control over their technologies and/or consumption. The term 'control elements' refers to the physical parts of the perceived or exercised form of control. It can, for instance, consist of technologies or software codes. Furthermore, a distinction is made between the physical control of the technology, the ability to manage the settings (control, for instance, by monitoring devices), and the sense of control. According to Langer (1975), people may have an illusion of control and believe that they have more control over the end results when they are actively involved in the process. Feeling in control may provide people with a sense of empowerment via the use of a technology that enables active involvement; likewise, people may feel a lack of control and a sense of being disempowered when they are not able to administer technology as intended. In our empirical analysis, we identify and discuss if/when people feel in control, situations in which they would have preferred to be (or not be) in control, and why they experience these feelings.

Despite the fact that smart grids offer an entirely new situation of control to households, few studies have focused on issues of control over and within a household (exceptions exist, e.g., Abi Ghanem \& Mander, 2014; Hargreaves et al., 2015; Nyborg, 2015'). This lack of research interest is a surprise because issues of control exist in all smart grid trials and affect all parties that install smart grid technologies. Although contextual characteristics usually hinder cross-country comparisons, issues related to control may be comparable and have a broader applicability: what people want to control at home and the extent of this control or their wish to be controlled may be less structurally defined and more personal, which generates generalizable ideas to consider when designing a smart grid trial or strategy. To provide an in-depth perspective on control issues, we investigated a smart grid trial with 20 Danish households that were equipped with smart grid technologies whose monitoring was performed by the company in charge of the installation (Insero) and the participating households. The remote control was conducted by Insero.

\section{Research question}

This study contributes rich empirical research on how control is adapted in households that are equipped with a large assortment of smart grid technologies. Because research on smart grid households and issues of control is scarce, this contribution is not only relevant for research in this field; through our human-centred, ethnographic research methodology and our use of the concept

Post-print version, please cite this paper as: Hansen, M., \& Hauge, B. (2017). Energy Research \& Social Science Scripting, control, and privacy in domestic smart grid technologies: Insights from a Danish pilot study. Energy Research \& Social Science, 25, 112-123. http://doi.org/10.1016/j.erss.2017.01.005 
of script, this paper also represents what Sovacool (2014) $)^{\mathrm{ii}}$ suggests is needed for further progress in energy research: putting humans before technology.

From December 2013 until May 2015, we investigated how issues of control were being scripted (Akrich, 1992) into the trial by the responsible project and the trial initiator (the company Insero) and how the technologies and control elements were de-scripted by the households that participated in the trial.

Both in-scription and de-scription may provide a more general understanding of what is at stake when smart grids are introduced into private homes. Thus, the purpose of our study was to investigate how the new situation of control and the new technologies influenced people's control over their own homes.

We consider the empirical data to be a case study that may produce new social, cultural, philosophical or technical insights by examining how control is planned into smart grid experimental projects by project designers, how smart grid technology affects human life and how people attempt (or do not attempt) to take control of the technology. In this trial, we investigated how smart grid technology that was installed in people's homes affected the residents. A major element of the trial involved control in the form of 'technological control' related to the integrated part of the technology but also the idea of 'being controlled'. Few studies have addressed the meaning of 'control' for people living with it and the implications of being controlled in smart grid experimental projects, which can be seen as studying people who enact and live out the vision of the smart grid' (Hargreaves et al., 2015). We present empirical data on how control was embedded in the technology, practised, perceived and employed by the residents. Before presenting the analysis, which substantially evolves around the control issues that relate to the smart grid technology, the concepts employed in the analysis are discussed. The following section briefly describes the applied data material and methods in this study, followed by a description of the concept of script (Akrich, 1992) and control, to highlight the essential characteristics of the concepts and situate 'control' in the context of private homes. By explaining the significance of the home to people, the importance of control by the residents is illustrated.

\section{Data material and methods}

A smart grid trial named 'Insero Live Lab' is the source of this research, and the participants involved include the technical contributors, viz., the producers and suppliers of the smart grid technology elements, such as HPs, EV, sun wells, censors, PVs, smart metres and the eButler monitoring system; public participants who reside in the region, including the community of

Post-print version, please cite this paper as: Hansen, M., \& Hauge, B. (2017). Energy Research \& Social Science Scripting, control, and privacy in domestic smart grid technologies: Insights from a Danish pilot study. Energy Research \& Social Science, 25, 112-123. http://doi.org/10.1016/j.erss.2017.01.005 
Hedensted (Hedensted Kommune), VIA University College and the Green Tech Centre; 20 private families and homes in the Stenderup community, which constituted the research site and test zone (Insero Live Lab); the Insero group, which is responsible for the development of software for the remote control and aggregator (Insero Software), investigating energy business solutions for the HPs (Insero Energy), investigating transport using electricity (Insero E-mobility), and managing the live lab, which included the installation process, managing the workers, and communication with the households; DTU, which is responsible for the research part and the aggregator; and funding agencies (EU, DTU).

The stage: Insero Live Lab is located in the village of Stenderup in Jutland. Over the last two years, beginning in December 2013, 20 households were equipped with a range of smart grid technologies, such as PVs, EVs, HPs and the home energy management system eButler. Because a number of the households had PVs prior to the trial, they employed the 'old' regulation scheme and received the same amount of money for their produced electricity as they received when purchasing, which was approximately $2 \mathrm{DKK} / \mathrm{kWh}$. The remaining households entered the new scheme and received 0.6 DKK/kWh. The households were connected in a smart grid, so specific equipment (charging stations, HPs and sensors) could be monitored and controlled by Insero Software via the Internet. The families in the project were very diverse in terms of age, gender, family status, and educational leveliii. To ensure confidentiality, the families were anonymous.

For this study, we employed a combination of different methods: a small survey among households and ethnographic methods (fieldwork that consists of observations in public meetings and private homes, semi-structured interviews, photos from people's homes, videos, and workshops ${ }^{\mathrm{iv}}$ ).

Phase 1 included the public meetings that were held prior to the trial, which are described in the results section. When a sufficient number of participants had committed to joining the Live Lab, the first round of interviews was scheduled ${ }^{v}$. To obtain demographic data, the informants were required to answer an online questionnaire in the same period.

In phase 2, interviews with the household members were conducted, and observations and photos were collected. The interviews occurred in the homes of the informants; the duration of each interview ranged between 50 and 90 minutes $^{\mathrm{vi}}$. In most cases, the informants demonstrated the use of the displays connected to the HP, PV, and eButler (energy management equipment) during a tour of the house. The main author participated in one workshop in January 2015 to discuss the new features of eButler. In the same period, four interviews were conducted with two eButler software designers and two Insero Software employees.

Post-print version, please cite this paper as: Hansen, M., \& Hauge, B. (2017). Energy Research \& Social Science Scripting, control, and privacy in domestic smart grid technologies: Insights from a Danish pilot study. Energy Research \& Social Science, 25, 112-123. http://doi.org/10.1016/j.erss.2017.01.005 
In phase 3, two workshops were arranged: the first was held in the home of a participating family, and the second was arranged in the local community hall. These locations were chosen to create a familiar atmosphere, in which participants were encouraged to voice their opinions and ask questions. In September 2015, two phone interviews were conducted.

Prior to the interviews, a semi-structured interview guide was prepared with a range of open-ended questions (Kvale, 2000). All interviews and workshops were audio-recorded, transcribed ${ }^{\text {vii }}$ and coded in Atlas.ti, which is based on a grounded approach (Strauss, 1987).

\subsection{Conceptual framework}

The conceptual framework for investigating the value of smart grid technology to the trial participants is the concept of script and control. We briefly describe each concept to explain how these concepts have been identified and employed in the empirical analysis.

\subsubsection{The notions of script, in-scription and de-scription}

Akrich and Latour proposed the concept of script to describe technical objects (Akrich, 1992; Akrich \& Latour, 1992; Mattozzi \& Piccioni, 2012). The concept was coined by Akrich:

"Thus, like a film script, technical objects define a framework of action together with the actors and the space in which they are supposed to act". More specifically she claims about the designers and their role in defining the artefact "[...] Designers thus define actors with specific tastes, competences, motives, aspirations, political prejudices, and the rest, and they assume that morality, technology, science, and economy will evolve in particular ways. A large part of the work of innovators is that of "inscribing" this vision of (or prediction about) the world in the technical content of the new object." (Akrich, 1992)

According to Akrich, a script is the end product of a designer's activity of in-scribing a vision of a potential user and the world in which the artefact will eventually work. The focus is the designers, and the artefact is the last element of this assemblage; the artefact only has to accommodate the script stemming from the designer's ideas. This viewpoint seems limited; the need for a more precise depiction of the designers' viewpoint of the user and a view of the technology has been suggested (Suchman, 2007). Others have made the criticism that the concept of script is too narrow (Verbeek, 2011; Fallan, 2008). Verbeek asks for a rich vocabulary to consistently and extensively utilize the concept and claims that the notion of script does not adequately address the mediation between the artefact and user, which suggests that 'delegation' and 'in-scription' should be considered a complex, reciprocal exchange between the artefact and user. Non-human entities

Post-print version, please cite this paper as: Hansen, M., \& Hauge, B. (2017). Energy Research \& Social Science Scripting, control, and privacy in domestic smart grid technologies: Insights from a Danish pilot study. Energy Research \& Social Science, 25, 112-123. http://doi.org/10.1016/j.erss.2017.01.005 
can also delegate tasks to human beings, as in this trial, and technological mediations may produce specific forms of user appropriation. Considering script only as the product of in-scriptions makes it reducible to human activity, which is not consistent with the symmetrical approach that Latour initially proposed (Mattozzi \& Piccioni, 2012). Akrich's initial script concept suggests that scripts are the product of in-scriptions; however, the eventual script is the result of an interaction among the following parties: designers who inscribe particular forms of mediation; users who have interpretations and forms of appropriations; and the technological artefacts, which occasionally produce unexpected forms of use and mediation. The scripting of the technology by the designers and the de-scripting of the technology performed by the users occurs "Once the artifact is displaced into sites of use, she (Akrich) argues, the work of the user becomes one of "de-scription" of recovering from the object a coherent program of action." (Suchman, 2007). To completely understand the co-evolvement of objects using a script analysis method, the aim is to move back and forth between the designers and users (Fallan, 2008). This concept has been employed to study user representation and evaluate the compliance between the user behaviour and the technology developed by designers. The main focus has been the layout of technologies in relation to the actual users, with an emphasis on mismatches between the intended and actual uses (Konrad, 2008).

To advance sustainable products, the concept of script has been investigated to create technologies that are increasingly sustainable, i.e., contribute to a decrease in the environmental burden caused by consumption. A technology's script can be investigated by three dimensions: force, scale and direction (Jelsma, 2003). The force of the script refers to the extent of the constraint that the script applies on a user's relevant behaviour. The weaker the script is, the larger the number of choices that the user has to align with the script to achieve a set goal. One example of a goal is to change the timing of the charging of an EV to periods when electricity is generated from wind. A strong script would not allow charging in periods without 'wind-electricity' on the grid, whereas a weaker script would also allow the user to charge during other periods, which can be accomplished by an override function. The scale of the script refers to the level at which the technological system is being redesigned. The technological system can be redesigned at a lower level, where households can have technologies that users buy and program to react to the amount of electricity obtained from wind in the system. In principle, they could use a timer, check the weather forecast and time their charging accordingly. On another scale, the aggregator, who is a new participant in the energy area, can offer to control the user's charging according to different goals. His/her motives in controlling the charging are related to gaining flexibility in the grid that can be traded. The latter situation, which includes the aggregator, involves change on a different scale and at a higher level, where the goal of charging whenever the wind is blowing can be

Post-print version, please cite this paper as: Hansen, M., \& Hauge, B. (2017). Energy Research \& Social Science Scripting, control, and privacy in domestic smart grid technologies: Insights from a Danish pilot study. Energy Research \& Social Science, 25, 112-123. http://doi.org/10.1016/j.erss.2017.01.005 
systematically satisfied. The last dimension, the direction, refers to how a script influences behaviour according to the values and rules in the socio-technical landscape. Consequently, the script can function along different rules and values in the socio-technical landscape, which changes the morality of society because 'morality is as much in the things we use as in the minds of people' (Jelsma, 2003: 103). Marres (2012) claims that the 'scripted object' has a normative effect because certain roles have been built into it by the designers. In relation to the script concept, normativity is a material event in which actions occur on the object level (Marres, 2012).

The idea that designers of technology carefully plan the future of users is controversial. The comparison between 'the use of a technological object' and a 'film script' has been regarded as insufficient, as the role of the user is more diverse and negotiated than the role of the user in a film script. Thus, developers cannot be as farsighted as described by Akrich (Suchman, 2007). To counter this critique, others have stressed that the script does not have to be purely psychical (and defined by the designers), as it is also socio-technical. In her de-scription description, Akrich stresses that links of interest to users are both technical and social (Fallan, 2008). Referring to Joerges (1999), Fatimah et al. (2015) highlights that designers are not the only people who shape new technologies or designs. Other elements, such as standards, policies and regulations of technologies, may also fill important roles in the outcome and use of a technology, and designers include these external elements in the in-scription of technologies. They emphasize that a script enables an investigation from multiple points of views from the participants. The concept enables a study of multiple de-scriptions of a project and multiple in-scriptions of entities to sustain a complete project (Fatimah et al., 2015); we employ this broader perception of script when analysing our empirical data, combined with the notions of control and home.

\subsubsection{Control}

Technologies have scripts, which are de-scripted via their use; this process may change the intended effect in the design. The interaction between technology and a user naturally involves a mutual impact and effect, particularly in the long term, as demonstrated by the invention of the freezer, which prompted new eating and food preparation habits (Shove \& Southerton, 2000). Technologies are imagined, designed and developed by people, which involves reflections and the inclusion of control elements. Control elements, the parts of a technology that enable people to have or take control over a technology (such as the visualization of consumption and some response options), may be more or less integrated in the technology, and the interaction may be more or less active/time-consuming. When analysing control situations and the interactions between people and their smart grid technologies, time has a natural role: the process of changing from a novice to a skilled practitioner requires time. We believe that a prolonged interaction

Post-print version, please cite this paper as: Hansen, M., \& Hauge, B. (2017). Energy Research \& Social Science Scripting, control, and privacy in domestic smart grid technologies: Insights from a Danish pilot study. Energy Research \& Social Science, 25, 112-123. http://doi.org/10.1016/j.erss.2017.01.005 
between technology and people may provide the best basis for identifying the person who is controlling the technology and when the technology is controlled, as well as potential shifts in who is in control. An investigation of control involves identifying the controlling part or controlling elements, who or what is being controlled, the purpose and extent of this control, and whether being controlled involves surveillance ${ }^{\text {viii }}$. These questions may be answered in a very contextualized setting; however, current society is characterized by complex technological interactions and transactions across the world (like energy trading), where technology may be cocreated using development processes, and technological regimes have the form of complex hybrids (Latour, 1991). Control may be an intricate and entangled matter that involves global networks, but it is also negotiated and 'taken' on a micro level when control is exercised over a smart grid system. Due to the increasing societal need for energy reduction and the expectations placed on the smart grid (Darby, Strömbäck \& Wilks, 2013), we believe that issues of control require not only an enhanced focus but also attention to the setting for this control: the home.

\subsubsection{Control and the smart grid at home}

Studies of control and smart grid households are scarce, and most studies only briefly mention control. However, the control of household appliances plays a role in visions of a smart grid. The Danish Smart Grid Network expects control equipment to be added to several household appliances:

"If control equipment is installed to reduce energy and electricity consumption by lights, pumps, heating, cooling, ventilation, IT servers and other electricity consumption, it will be relatively easy to add an additional facility for automatic control so that appliances etc. can be switched on or off according to price signals or some other remote control." (Danish Government, 2013)

Two main visions of control exist in relation to smart grids and households, namely, automatic control, in which appliances react to signals, and remote control, which is managed from outside the household. A consensus among engineers and software developers in the energy sector has not been reached regarding the role of automation and control in smart grid households (Strengers, 2013), and the significance of the home has attracted minimal attention in the design of smart grid technologies. This lack of attention may have been a mistake: research has shown that a sense of control over a resident's home and its appliances, products and technologies is important to residents; this control includes, for instance, being able to open the windows to air out the house and control the solar influx and indoor heating (Hauge, 2015). This finding not only relates to the need for residents to feel empowered and their ability to act based on a sense of

Post-print version, please cite this paper as: Hansen, M., \& Hauge, B. (2017). Energy Research \& Social Science Scripting, control, and privacy in domestic smart grid technologies: Insights from a Danish pilot study. Energy Research \& Social Science, 25, 112-123. http://doi.org/10.1016/j.erss.2017.01.005 
responsibility for the health of their family but also precisely reflects the characteristics of the home. The residential well-being is significantly dependent on controlling the indoor climate and cannot be isolated from the notion of the 'home,' which is described as a place to rest, a haven, a 'family project,' and an arena for activities (Aune, 2007) and the establishment and negotiation of not only relations (Gram-Hanssen \& Bech-Danielsen, 2004) but also practices (Hauge, 2013). Identity, control, freedom and self-determination are vital ingredients of a home (Blunt \& Dowling, 2006). These aspects are particularly important for the home, as the home is commonly the counterpart to the unstable and unpredictable world (such as working life or uncontrollable climate).

The new types of control that are introduced with a smart grid may influence the sense of control of householders over their homes. Scholars have investigated people's viewpoints on this issue in focus groups with household individuals who are in charge of their household's energy bill by discussing their viewpoints on remote control and different types of variable electricity prices. Studies have demonstrated that remote control had a negative impact on the sense of control of householders over their homes (Fell, Shipworth, Huebner \& Elwell, 2014).

Smart grid technologies and an increased level of control in the home can affect relationships within families. Previous research on smart grid experimental projects has demonstrated that smart grid devices can affect the control situations within families due to the increased surveillance of electricity consumption. As a smart grid entails the flexible consumption of electricity, it should involve flexible routines (Nyborg, 2015). To account for a new type of control in households in relation to smart home development, scholars have argued that smart home technologies should be designed to promote control over routines, planning and time rather than control over artefacts and devices (Davidoff et al., 2006). Thus, the development of new elements of control should be based on the needs of families in relation to flexibility in everyday life settings.

Scholars have argued that smart home technologies may provide finer control over household appliances but may also exert unwanted forms of control (Hargreaves et al., 2015). Hargreaves et al. (2015) identified three narratives that illustrate control in smart homes: the 'functional narrative' approaches control in a 'techno-centric' manner by focusing on how appliances can be controlled and the barriers to this control. The 'instrumental narrative' focuses on interactions between the user and the technologies and does not necessarily label control as being good, as is the case in the first narrative. The third narrative, the 'sociotechnical narrative,' assumes that control occurs within a smart home and must be considered as a part of society in a complex manner. After analysing households that have been transformed into smart homes, he concludes that "future research should simultaneously explore: what devices are being controlled in smart homes, through what types of user-interfaces, by whom and to what ends, how this interacts with prePost-print version, please cite this paper as: Hansen, M., \& Hauge, B. (2017). Energy Research \& Social Science Scripting, control, and privacy in domestic smart grid technologies: Insights from a Danish pilot study. Energy Research \& Social Science, 25, 112-123. http://doi.org/10.1016/j.erss.2017.01.005 
existing roles and dynamics within households and further, how control relationships beyond the home (e.g., to utilities, governments or research teams) impact on smart home usage." (Hargreaves et al., 2015: 13). In our empirical analysis, we identify control according to these questions with a focus on residents and their use of smart grid technologies at home. Governmental relationships and their impact on smart home usage are not addressed, as these issues are beyond the scope of our paper.

We highlight the significance of the home and the importance of residents in the trial to feel in control, as the setting for the smart grid and the remote control access is the home. The experience of feeling in control at home will rely on well-known technologies and routines. Although Akrich (1992) suggested that man-made technologies prescribe the behaviours of human users, these prescriptions are often ignored. Technology is frequently appropriated and domesticated in ways that counteract the designers' intentions (as discussed by Lie \& Sørensen, 1996). As indicated in our empirical analysis, in-scriptions were made during the entire trial from extensive interactions among many parties. We apply the script concept to describe this iterative process and combine this concept with a focus on control issues within the frame of the private home. By focusing on dynamic interactions, inscribing processes and specific control issues at home, we do not employ Latour's categories (Latour, 1992), which may have been applied to demonstrate inand de-scriptions in technology. Instead, we describe the process using three tracks that are identified in the empirical analysis and present this process in the results section: 1) How did the designers in-script control? 2) How did the users de-script control? and 3) How did the designers respond to the de-scription?

\section{Results}

We analyse the script and control issues on two levels: on the level of the designers and project owners (in-scribers) and on the household level (de-scribers). From the analyses of how control was in-scripted in the Insero Live Lab, we discovered that a certain collection of technologies was of particular interest to the responsible project because it allowed the remote control of the residential energy consumption. We analysed the script related to control issues in smart grid households by specifically investigating the remote control of the HPs and the charging of EVs in relation to PVs. We determined that 'the need for being in control' is an individual phenomenon and discovered that the participants had some difficulty adapting to the needs of the system. A common source of discontent involved the de-scription of the control technologies because they did not always function as expected by the participants. Once the residents realized that the control that was part of the setup did not meet their expectations in relation to being controlled, viz. to

Post-print version, please cite this paper as: Hansen, M., \& Hauge, B. (2017). Energy Research \& Social Science Scripting, control, and privacy in domestic smart grid technologies: Insights from a Danish pilot study. Energy Research \& Social Science, 25, 112-123. http://doi.org/10.1016/j.erss.2017.01.005 
reduce energy usage or alert them in situations in which the energy consumption was remarkably high, they expressed frustration and dissatisfaction, which indicates a mismatch between in- and de-scription.

\subsection{How did the designers in-script control?}

From an overall perspective, the company Insero's main interest in Insero Live Lab was to develop new innovative solutions to base new businesses on. Insero took part in a large EU-funded project FINESCE with the overall purpose of developing software related to 'the Internet of things' and the future energy sector. The project included a goal of creating new software for the control of energy. Based on these overall goals, the Insero Live Lab steering committee engaged in discussions on what technologies they wanted to develop control software for. Insero contains four subsidiary companies; one of these companies, Insero Software, was responsible for the development, implementation and management of the IT infrastructure to control the chosen technologies and offer flexibility to the grid, i.e., moving the energy consumption from peak periods. Thus, one core purpose of Insero Live Lab was to work with software developers to design and develop remote control for the electricity system of the future via smart grids. Another subsidiary company, Insero Energy, was interested in the control from a more practical point of view, including developing new business models and the knowledge of technologies that reduce greenhouse gas emissions.

\subsubsection{The initial idea in the trial}

Through internal negotiations, the steering committee decided that the main idea of Insero Live Lab was to test the remote control of electricity-consuming devices (EVs and HPs) combined with electricity-producing devices, PVs. This would entail the production of electricity in the households and its transfer to the grid at a time where electricity prices are relatively high. This combined with the remote control of the charging of the EV and the consumption of the HP would enable Insero to control the households according to the needs of the electricity grid. Moreover, this concept could benefit Insero by allowing them to optimize according to the Nord Pool Spot power market.

Insero had planned to install the same package of technologies in all the participating households. The initial package to be introduced included an air/water HP; an EV, including a charging station that could be remotely controlled (both the EV and charging station were to be leased for two years); and 6000-kW photovoltaic solar cells (PVs). As Insero Software, which develops software to remotely control EVs and HPs, did not have any experience in developing interfaces for the consumer side, Insero opted for an existing home energy management system, eButler, which would provide the consumer with an overview of their energy consumption and the means to manage it ${ }^{\mathrm{ix}}$.

Post-print version, please cite this paper as: Hansen, M., \& Hauge, B. (2017). Energy Research \& Social Science Scripting, control, and privacy in domestic smart grid technologies: Insights from a Danish pilot study. Energy Research \& Social Science, 25, 112-123. http://doi.org/10.1016/j.erss.2017.01.005 
These technologies formed the core and were to be installed in people's houses ${ }^{x}$ to enable Insero to test their flexibility in real-life energy consumption.

The carefully chosen technologies were to be tested in combination in a smart grid, in which all households could be monitored and externally controlled: "We wanted to create a system that we could monitor while at the same time take into account their preferences. We wanted to control the flow temperature but based on certain criteria that the participants had pre-defined. They could say: 'I want $21^{\circ} \mathrm{C}$ in the living room and the hot water to be $48^{\circ} \mathrm{C}$.' and whatever they would define we would respect. Nevertheless, it was important for us to be in control of the system." (Project responsible, Insero). By focusing on the existing technologies, they avoided the majority of the risks related to functionality encountered by novel technologies ${ }^{\mathrm{xi}}$.

Thus, to the project initiators, different issues of control were at stake: initially, they planned the remote control of the charge stations and HPs to dynamically optimize them according to electricity market fluctuations and to aggregate flexibility.

\subsubsection{Modification of the package, showcasing blurred boundaries of who is in control}

To create an awareness of the project and to attract participants, Insero arranged three public meetings in the village of Stenderup to investigate the interest among villagers in investment in these technologies. However, the inhabitants would not settle for the suggested packages. People were not satisfied with the EV and asked if it could be excluded. Because HPs and PVs are technologies that are often related to the renewal or modernization of homes, many of the participants had a clear idea of what types of new technologies they preferred. They were more interested in the process of negotiating what was possible and why. Substantial interest in the ground HPs and less interest in the preliminary air/water HPs recommended by Insero was observed. The choice of technologies was re-opened, and several new opportunities were discussed. Some of the households that initially wanted a ground HP did not succeed in installing such due to barriers such as a garden that was too small or insufficient access to the basement. A new alternative was included in the range of possible technologies: a hybrid HP (air/water and gas). A few families were keen on obtaining solar wells ${ }^{\text {xii }}$ instead of ground HPs; thus, two households had solar wells drilled on their premises. The public meeting opened up the possibility for the participating households to negotiate other solutions to be installed in their households, and Insero realized that to succeed in enrolling 20 households in the project, they needed to be open to such negotiation. In the following period, the participants negotiated with Insero and specialists

Post-print version, please cite this paper as: Hansen, M., \& Hauge, B. (2017). Energy Research \& Social Science Scripting, control, and privacy in domestic smart grid technologies: Insights from a Danish pilot study. Energy Research \& Social Science, 25, 112-123. http://doi.org/10.1016/j.erss.2017.01.005 
over which heating technologies would be installed in their houses to achieve the best solution according to comfort and price.

Because the legislation regarding PVs was undergoing changes, most participants could only have 4000-kW PVs installed. Additionally, they were promised a price of $1.3 \mathrm{kr} / \mathrm{kWh}$ for the delivery of electricity to the grid because this was the expected national price at the time.

The main differences between the initially proposed package of technologies and the actual installed technologies were the following: Instead of 20 households with the same air/water HP, it was installed in only 7 households. Of the remaining households, 8 received a hybrid air/water HP with a gas boiler installed, two households were equipped with sunwells and two households with a geothermal HP. Due to the participants' resistance to leasing an EV for two years, the period was changed from two years to one year.

The changes in the technology portfolio had consequences for the total setup and the related issues of control. The new type of HP (the hybrid form) had not been tested in Denmark, and the solar wells and ground HPs were not suitable for achieving flexibility due to the lower electricity consumption and other technical reasons.

The in-scription process at Insero Live Lab was dynamic and included negotiations between the residents and the project owners: the designers of the Live Lab had a specific vision of control that involved a certain type of technology and a feed-in tariff structure. This vision did not materialize because the participants were decisive with respect to the technologies that they wanted to have in their homes. Simultaneously, the feed-in tariff structure for the PVs changed, which caused difficulties in remote control. The final script of Insero Live Lab was not merely a product of the designers' visions but was best described as a negotiation process among the designers, participants and political decisions in the energy area. These dynamic negotiations may have prompted a higher sense of residential ownership of the system and contributed in shaping the residents' perception of control, as we illustrate in the following section.

\subsection{How did the users de-script control?}

In this section, we investigate how private consumers de-script new issues of control in their homes. First, we investigate the information/visualization equipment in the process; second, we investigate how the participants considered being remotely controlled; and third, we explore remote control and how it was de-scripted by the participants.

Post-print version, please cite this paper as: Hansen, M., \& Hauge, B. (2017). Energy Research \& Social Science Scripting, control, and privacy in domestic smart grid technologies: Insights from a Danish pilot study. Energy Research \& Social Science, 25, 112-123. http://doi.org/10.1016/j.erss.2017.01.005 


\subsubsection{Control via information/visualization equipment}

In this section, we show how information/visualization was part of the process of gaining control over the technologies ${ }^{\text {xiii }}$. The participants engaged in changing their consumption patterns according to their production of electricity ${ }^{\text {xiv }}$. In the process of load shedding, information/visualization equipment ${ }^{\mathrm{xV}}$ was employed to impact the consumption by providing immediate feedback to the residents. The families had different types of information/visualization equipment installed at home. They had access to eButler via the Internet, and each household had a profile from which they could retrieve information about their entire energy consumption and production per hour, day, week and month. On eButler, they could obtain information about their hourly/weekly/monthly consumption from the most consuming technologies: the EV and HP were separated from the remaining consumption, i.e., the lights, cooking and ICTs. eButler was accessible online and could be used independent of the location within the household. In addition to being informed of their production and consumption via eButler, the families could also directly obtain information concerning their production and consumption on the newly installed technologies via displays attached to the indoor components of the HPs and PVs. A similar case was the smart metre, which included a display integrated in the metre. These displays were primarily placed in a utility room or garage, and the information that can be obtained from these displays varies according to the technology to which they are connected. For instance, the HP display, which is depicted in figure 1, shows the consumption of electricity (and gas for the hybrid $\mathrm{HP}$ ) that is used to heat the house and water. In addition, it visualizes the available settings for the HP: the temperature curves and the nighttime-drop setting. The smart metre shows the purchase of electricity, how much electricity has been delivered to the grid (utility company) and the current use of electricity via a display attached to the metre.
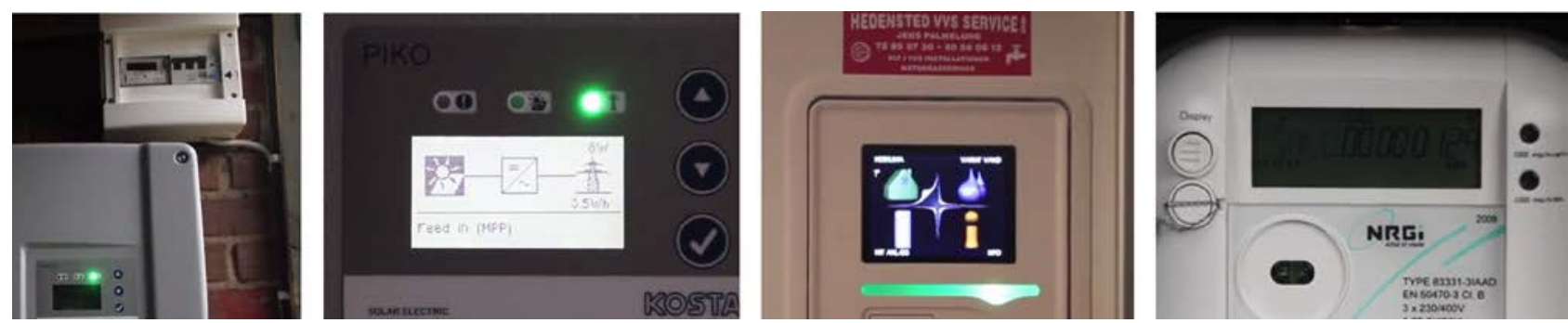

Figure 1. Examples of the displays installed in the $\mathbf{2 0}$ households. Left: The first and second photos resemble the inverter. The third photo shows the HP-display. The fourth photo shows the smart metre display (courtesy of Insero).

The PV inverter visualizes how much electricity has been produced (in $\mathrm{kWh}$ ) on the last day, during the last week, and the total since the installation. Some people used the PV inverter to obtain knowledge about the production of electricity. For residents, it served as a signal of when to begin charging their cars:

Post-print version, please cite this paper as: Hansen, M., \& Hauge, B. (2017). Energy Research \& Social Science Scripting, control, and privacy in domestic smart grid technologies: Insights from a Danish pilot study. Energy Research \& Social Science, 25, 112-123. http://doi.org/10.1016/j.erss.2017.01.005 
"We read what the inverter says when we come home and if there is any electricity being produced, then we might as well plug it in" (L13)

In this case, the inverter display was used as a signal for when to plug in the car. The actual number on the inverter display (kWh) had no significance, which is consistent with studies that suggest that the amount of energy in $\mathrm{kW}$ has a minimal importance in everyday life to many people (D'Oca, Corgnati, \& Buso, 2014). The information on the display was used by residents to determine if the PV was producing energy; if it was producing energy, they would start charging their cars. The immediate availability of the smart metre display contributed to the information obtained while they performed activities within the home:

W: "When we are doing some household activities we look at the metre, "what happens out here?', it is really great when it shows 0 (zero), despite the washing machine and oven are running and the car plugged in" (L13)

This family used the 'current electricity purchase' on the metre as a sign of electricity savings: when the metre indicated 0 , they knew that they were receiving the consumed energy without cost. Based on the metre readings, they adjusted their consumption and used the metre to control the number of devices they could switch on/off according to how much electricity they were producing from the PVs. Although their interest in learning about the current state of production and consumption was considerable, they did not use eButler to track their total energy situation because eButler was only available on a PC and they only sat in front of a PC once a week to conduct practical chores, such as paying bills; they were not interested in spending additional time there. Therefore, the displays on the inverter, the HP and the smart metre were more frequently used.

In addition to the ability to monitor their consumption and production, many of the families expressed distress about the fact that they were also confronted with information about the amount of electricity that they were donating to their energy company:

M: "We can see here what we produce during the day. Here we see how much electricity we buy, here we see how much electricity we sell. We are on the new billing account ${ }^{\mathrm{xvi}}$. We have to pay 1000 DKK to the energy company in administration fees. That's a bit annoying." (B2xx)

M: "This is how much we produce (looking at eButler), this is how much we deliver to the energy company. It's far too much." (P3)

Post-print version, please cite this paper as: Hansen, M., \& Hauge, B. (2017). Energy Research \& Social Science Scripting, control, and privacy in domestic smart grid technologies: Insights from a Danish pilot study. Energy Research \& Social Science, 25, 112-123. http://doi.org/10.1016/j.erss.2017.01.005 
Here, a dilemma regarding feedback was revealed: the participants were informed by the equipment about the consumption and production of electricity; however, some of the participants did not have the ability to make energy-related changes. Thus, this information was not considered constructive information but rather highlighted that they were not in control over the use of their produced electricity.

After 18 months, some of the participants believed that scrutinizing the data was a waste of their time. This opinion was especially expressed by busy families, who did not have spare time for eButler.

"I have used eButler 5 times, I think. It doesn't interest me at all. I neither have time nor interest to use eButler." (F6)

eButler enabled participants to investigate the consumption of specific devices. One example was the consumption of the EV and the investigation of specific issues, such as calculating the COPvalue $^{\text {xvii }}$ for the HP to ensure that optimal settings were attained:

"I have checked eButler every month to see how much I have produced and how much I have used. Also I have figured out that my HP has an average COP-value of 3 over a one year period." (P7)“Yes, and I have used night-time drop, and used eButler to see if it actually made sense."

This feedback occasionally caused frustration when families became aware of the unwanted use patterns by the HP:

M: "eButler told us that our HP runs during the night." F: "Between 4 and 6 am I think it was." M: "And that's not right. Why does it start then? 'Cause if the water is $45^{\circ} \mathrm{C}$ it is more than enough for us to shower. At 10 am the sun is shining, then it can begin to heat. We think that in the summer it should shut down and not use electricity when there's no sunshine.."(B2xx)

The residents' interest in controlling the devices appeared highly motivated by the displays. The displays were used to provide information about the current production and consumption. They were actively and more regularly employed than eButler because the displays were available at all times without the need to log on. By monitoring the displays, the families were actively turning technologies on/off according to the production of the PVs. The de-scription of the information/visualization equipment was used to control consumption according to the production of the PVs.

Post-print version, please cite this paper as: Hansen, M., \& Hauge, B. (2017). Energy Research \& Social Science Scripting, control, and privacy in domestic smart grid technologies: Insights from a Danish pilot study. Energy Research \& Social Science, 25, 112-123. http://doi.org/10.1016/j.erss.2017.01.005 
The de-scription of eButler primarily occurred among the technologically interested participants who had a significant interest in individually controlling the technologies, whereas the other participants rejected the script and had no interest in it. The de-scription of eButler also entailed frustration, as it presented the participants with facts about their lack of control over their consumption and technologies. Participants who wished for a finer control of the visualization technologies - such as a better overview of consumption - turned to eButler.

The internal dynamics and priorities in the families and their varying degrees of technological enthusiasm influenced the total interest in the smart grid project. For some families, the smart grid project became a common project within the family to control the devices according to the production of electricity from the PV: "It's like a sport". These families seemed more disturbed by the lack of control over the HP than those families who had less interest in technology.

\subsubsection{Control vs remote control technology}

When the residents were asked about the concept of remote control, they had differing ideas:

"The more the devices are controlled by others, the less it becomes something that we feel a sense of ownership of. And there's something about having these devices yourself, that there are some technologies you have and that you can provide yourself with energy and that you would like to control how it should work." (L15)

This family had the time to control the temperature in the house on a daily basis; they were keen on changing the settings in the house to accommodate the new system, highly interested in the environment and determined to control their consumption and be 'green.' Others had busy family lives and did not have extra time or energy to comply with the environmental goals. As one family man stated,

M: "..The more the technologies can control themselves the better; they (automatic technologies) are better at it. That is why it's called automatic." (P3)

Significant differences in the amounts of time different families invested in the control of their heating systems were observed. The majority of the families did not mind if someone else controlled their devices as long as the comfort settings were considered and appropriate. As one of the participants noted,

“..I don't consider it any different if it's a computer at home that controls the temperature, or if this control is placed with Insero. As long as the temperature is $23^{\circ}$ $\mathrm{C}$, which they promised, then it is ok." (B2xx)

Post-print version, please cite this paper as: Hansen, M., \& Hauge, B. (2017). Energy Research \& Social Science Scripting, control, and privacy in domestic smart grid technologies: Insights from a Danish pilot study. Energy Research \& Social Science, 25, 112-123. http://doi.org/10.1016/j.erss.2017.01.005 
The participants also discussed who had control of the devices. If a person in the household defines the temperature, is that person in control or is the energy company that acts within these boundaries in control?

"The question is if they are going to control it, or who is in control? If you can change the setting in periods as you wish, are you then the one in control?" (S2)

Thus, the script and the setting of the boundaries seemed to give many of the participants the feeling of being in control because they were able to set the boundaries. Many families believed that it did not matter whether the control unit was placed in the home or located at the energy company. The idea of being externally controlled gave some informants a sense of safety. They reflected on the fact that having external control could help maintain a correct indoor temperature when they were away from home and facilitated heating their house before they returned home after a holiday. The increased level of control and discussions about control related to the data from the household caused the participants to question their advantages in this set-up:

"M: I have been wondering, since we are talking about control, is anyone keeping track of our consumption? Are they saying, 'this looks all wrong'? Right from the beginning I had the feeling that we were really being 'watched' with the different technologies, but as my mum says, if that was the case then the technologies should have worked" I: "So you would have liked more focus on finding the problems?" M: "Otherwise, what are all the measuring devices for?" (B2xx)

Some of the participants were disappointed in the lack of feedback from the results of the surveillance. They wondered if information was missing from the household data collection. Other participants had experienced malfunctions in the HP and were disappointed that they had discovered the problem instead of the energy company:

"It was pure luck that he (a technician) came that day. Because if 2-3 weeks had gone by and the HP had been running on the heating element during all that time, then we would have received a huge electricity bill. It would have been nice if someone surveilling the system would pay attention to when we all of a sudden used the double amount of electricity." (P7)

The promise of remote control had apparently made them feel safer with reference to these problems. The initial feeling of trust towards Insero may have been betrayed because they initially were confident that the company also regularly checked the system for malfunctions. Thus, a discrepancy between the expectations of the informants with respect to the concept of remote

Post-print version, please cite this paper as: Hansen, M., \& Hauge, B. (2017). Energy Research \& Social Science Scripting, control, and privacy in domestic smart grid technologies: Insights from a Danish pilot study. Energy Research \& Social Science, 25, 112-123. http://doi.org/10.1016/j.erss.2017.01.005 
control and the responsibilities of Insero was observed. The participants were significantly motivated by reliability in relation to remote control, whereas Insero was more focused on flexibility issues; this discrepancy revealed a mismatch in the script regarding control. How the participants de-scripted the notion of control and what should be included is illustrated in the following quote:

"We have those sensors in the rooms; then I see it as natural that they look if it runs alright. Or are they just letting everything run without even keeping an eye on what is going on? There must be a reason for why we have sensors in various rooms." (P7)

Some participants reported that their self-production of energy was connected to a wish to control the devices; thus, they rejected the script of remote control. They would rather decide when to charge their car and did not want Insero to remotely control their HPs. Other participants had more faith in the technologies and the employees who performed the remote control than in their ability to learn how to control these devices according to best practices. Most participants did not seem to be concerned with who exerted the control; as long as they were able to apply their settings, they did not care about the physical location of the computer. The external control also made some participants feel safer because other people with more technological skills could also detect problems within the household.

De-scripting the technologies and the new situation of control revealed that the participants' notions of control were not commensurate with Insero's notion of control. Although the participants expected to have an increased perception of safety as a part of being increasingly monitored, they discovered that this expectation was not always fulfilled, which caused frustration.

\subsubsection{Living with remote control}

As part of the project, the households had agreed to allow their EVs and HPs to be remotely controlled. The remote control of the EV began slightly more than one year after the technologies were installed. Some of the households did not notice when the remote control began:

"I didn't realize that it'd been remotely controlled until I checked eButler." (L13)

Other participants experienced their car turning off before the charging was finalized, which slightly unnerved some of the informants:

"In the beginning I was kind of nervous. We had some problems with the charger when it just got installed. It wasn't easy to figure out if it was because of the same problems that we had experienced earlier or if it was because they had begun controlling it" (P7)

Post-print version, please cite this paper as: Hansen, M., \& Hauge, B. (2017). Energy Research \& Social Science Scripting, control, and privacy in domestic smart grid technologies: Insights from a Danish pilot study. Energy Research \& Social Science, 25, 112-123. http://doi.org/10.1016/j.erss.2017.01.005 
There was substantial interest in charging the EV when the sun was shining, which was not consistent with the original idea of the project. The EV and HP were to be turned on during the night when electricity was inexpensive, and the electricity produced during the daytime was to be fed to the grid.

"..We ended up using a lot of extra money on the charging of the EV. We actually plugged the car in while the PVs were producing electricity. But you see, they were postponing the charging until the night" (S4)

The informants were dissatisfied with the issue of not being able to control the EV according to the PV's production of electricity. Because the informants had changed their routines to consume as much of their produced electricity as possible, they were annoyed when Insero began to externally control their EV, although this process was consistent with the initial project plan and agreement. Some participants created ways to work around it by turning the plug on and off a couple of times until it began recharging:

"It didn't work a couple of times, but then I figured out that I should just leave it turned on when I pulled the plug out...and when I re-plugged the EV, it started charging again" (S2)

Additionally, the remote control of the charging failed in a few cases, which caused the participants to become suspicious. They took precautions when they had important plans:

"Sometimes in the morning it was only charged to $24-25 \%$. Some mornings when I had to leave early I pulled a cable pool and charged with the guest charger during the night to make sure that it was charged" (F15)

Although an override function was available, many of the participants did not use it because it required too much work. When asked about the override function, one participant replied: "Well it was such a hassle. It was in eButler you could access it, but I never got around using it." (D22). They tended to use other methods to control the charging if the need arose. In general, the participants did not approve of the idea of having their EVs remotely controlled. This opinion was partly linked to the driving range of the EVs:

"If you drive an EV with a range of $130-140 \mathrm{~km}$ on a fully charged battery, then it mustn't occur that it's only charged $30-40 \%$ when you want to use it. So when you plug it in, it has to charge up to $80 \%$. Otherwise it needs to be a Tesla with a range of 400-500 km" (F15)

Post-print version, please cite this paper as: Hansen, M., \& Hauge, B. (2017). Energy Research \& Social Science Scripting, control, and privacy in domestic smart grid technologies: Insights from a Danish pilot study. Energy Research \& Social Science, 25, 112-123. http://doi.org/10.1016/j.erss.2017.01.005 
This opinion was also connected to the time schedules of the families. Some families were under pressure time-wise such that it was impossible to avoid charging during peak hours in the grid:

"I couldn't live with the EV not being charged between 4-6 pm. Because I'm often at home an hour before I have to pick up the kids from football practice. Then it needs all the electricity it can get." (F6)

Because the script of remote control was normative and induced actions of leaving the control of the charging to Insero, it proved to be unwanted by many participants, who were entirely dependent on their cars because they resided in the countryside. The de-scripting of the new technologies by the families and their goal of the consumption of electricity according to production clashed with the inscribed moral of passivity in the script of remote control. Some participants acted against the script of remote control if they were especially dependent on the EV the next morning.

\subsection{How did Insero respond to the users' de-scription of control?}

Several learning points were reported by Insero when Insero Live Lab ended. The results spanned from user involvement to implications for the electricity grid. According to the control aspects, Insero reported that the consumers were more interested in the remote control of their HPs than the remote control of their EVs, as the participants reported feeling safer when experts controlled their HP. The remote control of the EV, however, was not linked to an increase in reliability; rather, the opposite viewpoint was held: the remote control of the EV was linked to a decrease in reliability. Consumers felt that they lost control over something on which they were entirely dependent (Diekerhof, Drysdale, Hoffmann, \& Jorgensen, 2015). Thus, the results of the project report were aligned with the results obtained via the interviews and workshops.

Insero reported that their choice of technologies, the PVs, had caused problems ${ }^{\text {xviii }}$ that conflicted with the original visions of the Live Lab:

"There were some big challenges connected with the fact that the earnings from the PVs were so low. And that is why they [participants] wanted to control the HP, and run the dishwasher in the middle of the day. That was for sure not what we intended because we went out to optimize according to an electricity price on the spot market and not what was privately economically feasible. " (Insero project responsible)

The change in the script by another participant, through governmental regulations, thus changed the de-scription by the consumers in relation to the control. They wanted to use electricity

Post-print version, please cite this paper as: Hansen, M., \& Hauge, B. (2017). Energy Research \& Social Science Scripting, control, and privacy in domestic smart grid technologies: Insights from a Danish pilot study. Energy Research \& Social Science, 25, 112-123. http://doi.org/10.1016/j.erss.2017.01.005 
differently (than Insero had originally anticipated), which caused the smart grid visions for flexibility to collapse; this collapse had not been expected before the project was initiated.

Based on Live Lab, Insero Energy chose to create a new business that focused on the least engaged customers. Insero Energy made the following statements about the new business and the results of the Insero Live Lab:

"It is important that consumers do not control and monitor the HP themselves, they must simply regard the HP as black-boxed, so it's important to us to get that particular kind of consumers and those types we did not have in the Living Lab" (Insero project responsible)

Due to the combination of technologies and the fact that the participants wanted to control their devices according to their PVs, they did not become the type of consumer that would warrant the formation of a new business based on the given current situation in Denmark. With the current structure of the energy system, the increased desire to control the technologies due to the PVs is not compatible with the planned remote control that Insero had in-scripted.

\section{Discussion and concluding remarks}

In this study, we demonstrated how the participants de-scripted the new situation of control when an extensive combination of smart grid technologies was installed in their homes. Based on the contradiction between how the participating households behaved and the electricity system's needs, the roles of future energy consumers or energy citizens warrants discussion.

We found very different understandings and goals of what should be controlled and why between Insero and the living lab participants. While Insero had planned the project with a particular set of control elements, energy system and energy consumers in mind, the result turned out rather different. The participants demanded a different technological set up, the feed-in-tariff structure changed and the participants reacted swiftly to new regulations. Insero seemed to have the impression that the participants would be content with being controlled. To some extent, this was true, but the participants accepted remote control over some technologies but not others and they wanted more information and security from the installed technology than was being delivered to them. It became apparent how control situations are easily changed because of regulation and the participants' wish of feeling in control.

Using Jelsma's (2003) dimensions of the script concept to investigate the concept of remote control, the force of the script that relates to remote control in the Insero Live Lab appeared to be

Post-print version, please cite this paper as: Hansen, M., \& Hauge, B. (2017). Energy Research \& Social Science Scripting, control, and privacy in domestic smart grid technologies: Insights from a Danish pilot study. Energy Research \& Social Science, 25, 112-123. http://doi.org/10.1016/j.erss.2017.01.005 
strong, i.e., the consumers could not easily change the timing of the remote control. They had the ability to override the remote control of the EV via eButler, but the function was too complicated to most consumers. In general, the information/visualization equipment provided the households with information that they could use to control their devices. Thus, some participants became more aware of the actions required to consume their generated electricity, which enforced their desire to gain control of the timing of the consumption. This finding was counterproductive to the main idea of the remote control and the aggregator in Insero Live Lab, who preferred that consumers not be concerned with their energy consumption. From their viewpoint, users should preferably be disengaged from their energy system, with a strong script in which consumers set some temperature boundaries but otherwise delegated the control to the aggregator.

As previously mentioned, the scale of the script related to the remote control in Insero Live Lab can be considered to change on a high level in relation to sustainability, as it requires both changes within the devices and a new actor, the aggregator, for it to function compared to a situation in which flexibility should be achieved by feedback to the consumers. Furthermore, the remote control had some built-in features that increased sustainable consumption since they could consume more electricity from wind power and when the prices of energy were low. Even if the scale of the script can be considered high compared to a situation where flexibility is achieved with feedback on energy consumption, the participants still had a say in the consumption patterns. Thus, the control system was not 'black boxed' in Insero Live Lab, although some technologies were easier for the users to override in relation to the control than others.

The direction in which the script of remote control in Insero Live Lab promotes values and rules in society can be connected to the values of the 'passive consumer' within the smart grid in Denmark. How do we envision and configure users in relation to flexible energy consumption and remote control? The results indicate that households that invest in PVs and EVs do not have incentives to contribute on a system level in Denmark in the current situation. Based on a discussion of energy citizenship and energy consumers, the control in-scriptions from Insero Live Lab can be considered to promote values in society towards continuing the current role of the energy consumer "..from whom energy is simply a good to be expended in pursuit of personal goals" (Goulden et al., 2014: $24)$, as they preferably would not interfere with the system. The de-scripting from participating households exhibited signs of energy citizenship, in which they engaged with energy as a meaningful part of their practices.

Thus, our study supports previous studies that reveal that control in a smart grid may imply unwanted types of control for household users (Davidoff et al., 2006; Hargreaves et al., 2015). This study contributes an understanding of the difficulties that utilities and smart grid experimental Post-print version, please cite this paper as: Hansen, M., \& Hauge, B. (2017). Energy Research \& Social Science Scripting, control, and privacy in domestic smart grid technologies: Insights from a Danish pilot study. Energy Research \& Social Science, 25, 112-123. http://doi.org/10.1016/j.erss.2017.01.005 
projects encounter when attempting to exert certain types of control on household users. The study has highlighted numerous meanings of control among residents and demonstrated that taking control of energy-consuming routines in everyday life - to change habits - seems to require a practical effort that all families may not be able to provide. The study also illustrated some discrepancies between the expectations of residents who allow energy companies to remotely control their energy systems and the capabilities of the system. When some residents wondered why they had not been informed about an extraordinary excess in consumption, their surprise was a result of their agreement about control, which granted access to their private homes. Considering the notion of 'home' and its characteristics, access to the private sphere is based on trust. This agreement and the residents' relationships to the controlling part, Insero, appear unbalanced and exert institutional control when consumers are not informed. If the resident must be controlled and has accepted this control by entering into an agreement, this control must be constructive for them and their home. Thus, the residents' idea of remote control seems to involve a desire for mutual respect because mutual respect provides meaning for the technological control over their private, everyday life.

This research calls for more attention to be given to new control situations for flexible consumers living with smart grid technologies. Referring back to Davidoff et al. (2006), further investigation is needed on the different types of smart grid devices and how they impact the often-messy nature of family life. More attention should be paid in the early phases of such projects to the actual lives of families and the need for variations in the design of control elements in the technological setup. This research proves how difficult it is to create projects that truly challenge the existing electricity system and involved institutions. We call for more projects along these lines that question the current role of households in the energy system.

\section{Acknowledgements}

We are grateful for the chance to work with Insero Live lab and would like to thank the employees from Insero and the informants for taking the time to provide the necessary support and data and guided tours and dialogue, respectively. In particular, we would like to thank Munna HoffmannJørgensen, Insero Business Services, for valuable insights in the project setup and knowledge sharing that has been central for our research. We also thank the four anonymous reviewers for their very useful and constructive comments. This research was funded by the iPower project (The Danish Council for Strategic Research and the Danish Council for Technology). The content of this paper is the sole responsibility of the authors and does not represent the view of the iPower project or involved partners.

Post-print version, please cite this paper as: Hansen, M., \& Hauge, B. (2017). Energy Research \& Social Science Scripting, control, and privacy in domestic smart grid technologies: Insights from a Danish pilot study. Energy Research \& Social Science, 25, 112-123. http://doi.org/10.1016/j.erss.2017.01.005 


\section{References}

Abi Ghanem, D., \& Mander, S. (2014). Designing consumer engagement with the smart grids of the future: bringing active demand technology to everyday life. Technology Analysis \& Strategic Management.

Akrich, M. (1992). The De-Scription of Technical Objects. In J. L. Wiebe E. Bijker (Ed.), Shaping Technology/building Society: Studies in Sociotechnical Change.

Akrich, M., \& Latour, B. (1992). A summary of a Convenient Vocabulary for the Semiotics of Human and Nonhuman Assemblies. In J. Bijker, W. \& Law (Ed.), Shaping Technology/ Building Society Studies in Sociotecnical Change (pp. 259-264). The MIT press.

Aune, M. (2007). Energy comes home. Energy Policy, 35, 5457-5465.

Balta-Ozkan, N., Watson, T., Connor, P., Axon, C., Whitmarsh, L., Davidson, R., Taylor, G. (2014). UKERC Scenarios for the Development of Smart Grids in the UK Synthesis Report Scenarios for the Development of Smart Grids in the UK - Synthesis Report. London.

Blunt, A., \& Dowling, R. (2006). Home. London: Routledge.

Broman Toft, M., Schuitema, G., \& Thøgersen, J. (2014). The importance of framing for consumer acceptance of the Smart Grid: A comparative study of Denmark, Norway and Switzerland. Energy Research \& Social Science, 3, 113-123.

Buchanan, K., Russo, R., \& Anderson, B. (2014). Feeding back about eco-feedback: How do consumers use and respond to energy monitors? Energy Policy, 73, 138-146.

Davidoff, S., Lee, M. K., Yiu, C., Zimmerman, J., \& Dey, A. K. (2006). Principles of Smart Home Control. Proceedings of the 8th International Conference on Ubiquitous Computing, 19-34.

Danish Government (2013). Smart Grid-Strategi - fremtidens intelligente energisystem. Copenhagen: Danish Ministry of Climate, Energy and Building \& Danish Government.

Darby, S., Strömbäck, J., \& Wilks, M. (2013). Potential carbon impacts of smart grid development in six European countries. Energy Efficiency, 6(4), 725-739.

D'Oca, S., Corgnati, S. P., \& Buso, T. (2014). Smart meters and energy savings in Italy: Determining the effectiveness of persuasive communication in dwellings. Energy Research \& Social Science, 3, 131142.

Diekerhof, M., Drysdale, A., Hoffmann, M., \& Jorgensen, C. (2015). D2.7-Horsens trial-v1.0 Trial Results (Vol. 1).

European Commission. (2011). Smart Grids: from innovation to deployment. COMMUNICATION FROM THE COMMISSION TO THE EUROPEAN PARLIAMENT, THE COUNCIL, THE EUROPEAN ECONOMIC AND SOCIAL COMMITTEE AND THE COMMITTEE OF THE REGIONS. Brussels.

Post-print version, please cite this paper as: Hansen, M., \& Hauge, B. (2017). Energy Research \& Social Science Scripting, control, and privacy in domestic smart grid technologies: Insights from a Danish pilot study. Energy Research \& Social Science, 25, 112-123. http://doi.org/10.1016/j.erss.2017.01.005 
Fadaeenejad, M., Saberian, a. M., Fadaee, M., Radzi, M. a. M., Hizam, H., \& AbKadir, M. Z. a. (2014). The present and future of smart power grid in developing countries. Renewable and Sustainable Energy Reviews, 29, 828-834.

Fallan, K. (2008). De-scribing Design: Appropriating Script Analysis to Design History. Design Issues, 24(4), 61-75.

Fatimah, Y. A., Raven, R. P. J. M., \& Arora, S. (2015). Scripts in transition: Protective spaces of Indonesian biofuel villages. Technological Forecasting and Social Change, 99, 1-13.

Fell, M. J., Shipworth, D., Huebner, G. M., \& Elwell, C. a. (2014). Exploring perceived control in domestic electricity demand-side response. Technology Analysis \& Strategic Management, 26(10), 1118-1130.

Foucault, M. (1977). Discipline and Punish: The Birth of the Prison. London: Penguin Books.

Goulden, M., Bedwell, B., Rennick-Egglestone, S., Rodden, T., \& Spence, A. (2014). Smart grids, smart users? The role of the user in demand side management. Energy Research \& Social Science, 2, 21-29.

Gram-Hanssen, K., \& Bech-Danielsen, C. (2004). House, home and identity from a consumption perspective. Housing, Theory and Society, 21(1), 17-26.

Hansen, M., \& Hauge, B. (2016). Prosumers and smart grid technologies in Denmark; Developing user competences in smart grid households. (Unpublished manuscript)

Hargreaves, T., Hauxwell-, R., Stankovic, L., Murray, D., Kane, T., Firth, S., \& Wilson, C. (2015). Smart homes, control and energy management: How do smart home technologies influence control over energy use and domestic life ? In European Council for an Energy Efficient Economy (ECEEE) 2015 Summer Study on Energy Efficiency (pp. 1021-1032).

Hargreaves, T., Nye, M., \& Burgess, J. (2013). Keeping energy visible? Exploring how householders interact with feedback from smart energy monitors in the longer term. Energy Policy, 52(2013), 126-134.

Hauge, B. (2013). The air from outside: Getting to know the world through air practices. Journal of Material Culture, 18(2), 171-187.

Hauge, B. (2015). Lives under the Sun: The Sensory Qualities of Daylight in Designing the Everyday. The Senses and Society, 10(1), 71-91.

Intelligent Energistyring AmbA, Teknologisk Institut, Exergi Partners, Neogrid Technologies, Eurisco, ArosTeknik, Insero Energy. (2015). Styr Din VarmePumpe vers. 2.

Jelsma, J. (2003). Innovating for Sustainability: Involving Users, Politics and Technology. Innovation: The European Journal of Social Science Research, 16(2), 103-116.

Joerges, B. (1999). Do politics have artefacts. Social Studies of Science, 29(3), 411-31.

Konrad, K. (2008). Dynamics of Type-based Scenarios of Use : Opening Processes in Early Phases of Interactive Television and Electronic Marketplaces. Science Studies, 21(2), 3-26.

Post-print version, please cite this paper as: Hansen, M., \& Hauge, B. (2017). Energy Research \& Social Science Scripting, control, and privacy in domestic smart grid technologies: Insights from a Danish pilot study. Energy Research \& Social Science, 25, 112-123. http://doi.org/10.1016/j.erss.2017.01.005 
Kvale, S. (2000). InterView. København: Reitzel.

Langer, E. (1975) The illusion of control. J Pers Soc Psychol ;32(2):311-28

Latour, B. (1991). Technology is Society Made Durable. In J. Law (Ed.), A Sociology of Monsters. Essays on Power, Technology and Domination (pp. 103-131). The Sociological Review.

Latour, B. (1992). Where are the missing masses? The sociology of a few mundane artifacts. Shaping Technology/Building Society: Studies in Sociotechnical Change, 151-180.

Lie, M., \& Sørensen, K. H. (1996). Making technology our own? Domesticating Technology into Everyday Life. Oslo, Norway: Scandinavian University Press.

Lunde, M., Røpke, I., \& Heiskanen, E. (2015). Smart grid: hope or hype? Energy Efficiency.

Mäkinen, L.A. 2016. Surveillance On/Off: Examining Home Surveillance Systems From The User's Perspective. Surveillance \& Society 14(1): 59-77.

Marres, N. (2012). The Environmental Teapot and Other Loaded Household Objects: Reconnecting the Politics of Technology, Issues and Things. In N. T. and K. W. P Harvey, E Casella, G Evans, H Knox, C McLean, E Silva (Ed.), Objects and Materials: A Routledge Companion. London and New York: Routledge.B

Mattozzi, A., \& Piccioni, T. (2012). A Depasteurization of Italy ? Mediations of Consumption and the Enrollment of Consumers within the Raw-Milk Network. Sociologica, 1-70.

Moura, P. S., López, G. L., Moreno, J. I., \& Almeida, A. T. De. (2013). The role of Smart Grids to foster energy efficiency. Energy Efficiency, 621-639.

Nyborg, S., \& Røpke, I. (2011). Energy impacts of the smart home - conflicting visions, 1849-1860.

Nyborg, S. (2015). Pilot users and their families : Inventing flexible practices in the smart grid. Science \& Technology Studies, 28(3), 54-80.

Schick, L., \& Gad, C. (2015). Flexible and inflexible energy engagements-A study of the Danish Smart Grid Strategy. Energy Research \& Social Science.

Shove, E., \& Southerton, D. (2000). Defrosting the Freezer: From Novelty to Convenience: A Narrative of Normalization. Journal of Material Culture, 5(3), 301-319.

Smith, G. J. D (2007). Exploring Relations between Watchers and Watched in Control(led) Systems: Strategies and Tactics. In Surveillance \& Society, 4(4): 280-313

Sovacool, Benjamin K. 2014. "What Are We Doing Here? Analyzing Fifteen Years of Energy Scholarship and Proposing a Social Science Research Agenda." Energy Research \& Social Science 1:1-29

Strauss, A. L. (1987). Qualitative Analysis for social scientists. Cambridge: CAMBRIDGE UNIVERSITY PRESS.

Post-print version, please cite this paper as: Hansen, M., \& Hauge, B. (2017). Energy Research \& Social Science Scripting, control, and privacy in domestic smart grid technologies: Insights from a Danish pilot study. Energy Research \& Social Science, 25, 112-123. http://doi.org/10.1016/j.erss.2017.01.005 
Strengers, Yolandes. 2013. Smart Energy Technologies in Everyday Life - Smart Utopia? London: Palgrave Macmillan.

Suchman, L. (2007). Human-Machine Reconfigurations - Plans and Situated Actions, 2nd Edition (2nd ed.). Cambridge: Cambridge University Press.

Van Dam, S. S., Bakker, C. a., \& Buiter, J. C. (2013). Do home energy management systems make sense? Assessing their overall lifecycle impact. Energy Policy, 63, 398-407.

Verbeek, P. P. (2011). Moralizing Technology, Understanding and Designing the Morality of Things. Chicago: University of Chicago Press.

Verbong, G. P. J., Beemsterboer, S., \& Sengers, F. (2013). Smart grids or smart users? Involving users in developing a low carbon electricity economy. Energy Policy, 52, 117-125.

Wilson, C., Hargreaves, T., \& Hauxwell-Baldwin, R. (2014). Smart homes and their users: a systematic analysis and key challenges. Personal and Ubiquitous Computing, 19, 463-476.

\footnotetext{
' However, none addresses an intervention that involves a combination of photovoltaic solar cells (PVs), electric vehicles (EVs), heat pumps (HPs), and remote control, including a high degree of complexity, as investigated in this research project.

ii Compared with authors in this field, our backgrounds seem unusual: We are women; one of us has a background in Design Engineering \& Innovation, and one of us is an experienced anthropologist.
}

\begin{tabular}{|c|c|c|c|c|c|c|}
\hline ID & $\begin{array}{l}\text { PV feed-in } \\
\text { tariffs: } \\
\text { Old/New* }\end{array}$ & $\begin{array}{l}\text { Gender } \\
\text { and age }\end{array}$ & $\begin{array}{l}\text { Children living } \\
\text { at home }\end{array}$ & $\begin{array}{l}\text { Socio-economic } \\
\text { status }\end{array}$ & Education & Installed technologies \\
\hline F27 & Old & $\begin{array}{l}M(35-44) \\
F(35-44)\end{array}$ & $\begin{array}{l}F(15-19) \\
M(5-9)\end{array}$ & $\begin{array}{l}\text { Wage earner } \\
\text { No information }\end{array}$ & $\begin{array}{l}\text { College } \\
\text { No information }\end{array}$ & $\begin{array}{l}\text { Hybrid Air/water HP with } \\
\text { gas boiler; PV; EV }\end{array}$ \\
\hline F33 & Old & $\begin{array}{l}M(45-54) \\
F(45-54)\end{array}$ & - & $\begin{array}{l}\text { Self-employed } \\
\text { Self-employed }\end{array}$ & $\begin{array}{l}\text { Lower secondary school } \\
\text { Lower secondary school }\end{array}$ & Air/water HP; PV; EV \\
\hline F6 & Old & $\begin{array}{l}M(35-44) \\
F(35-44)\end{array}$ & - & $\begin{array}{l}\text { Wage earner } \\
\text { Wage earner }\end{array}$ & $\begin{array}{l}\text { Vocational education } \\
\text { College }\end{array}$ & Air/water HP; PV \\
\hline P7 & Old & $\begin{array}{l}M(55-64) \\
F(55-64)\end{array}$ & $F(10-14)$ & $\begin{array}{l}\text { Unemployed } \\
\text { Wage earner }\end{array}$ & $\begin{array}{l}\text { College } \\
\text { College }\end{array}$ & $\begin{array}{l}\text { Hybrid Air/water HP with } \\
\text { gas boiler; PV; EV }\end{array}$ \\
\hline $\mathrm{H} 6$ & Old & $\begin{array}{l}M(45-54) \\
F(45-54)\end{array}$ & $\begin{array}{l}M(15-19) \\
M(15-19)\end{array}$ & $\begin{array}{l}\text { Wage earner } \\
\text { Wage earner }\end{array}$ & $\begin{array}{l}\text { University education } \\
\text { College }\end{array}$ & $\begin{array}{l}\text { Hybrid Air/water HP with } \\
\text { gas boiler; PV }\end{array}$ \\
\hline$B 3 x x$ & New & $\begin{array}{l}\mathrm{M}(65+) \\
\mathrm{F}(65+)\end{array}$ & - & $\begin{array}{l}\text { Retired } \\
\text { Retired }\end{array}$ & $\begin{array}{l}\text { Vocational education } \\
\text { Vocational education }\end{array}$ & Air/water HP; PV; EV \\
\hline$B 2 x x$ & New & $\begin{array}{l}M(35-44) \\
F(35-44)\end{array}$ & $\begin{array}{l}F(10-14) \\
F(10-14)\end{array}$ & $\begin{array}{l}\text { Wage earner } \\
\text { Wage earner }\end{array}$ & $\begin{array}{l}\text { Vocational education } \\
\text { Vocational education }\end{array}$ & $\begin{array}{l}\text { Air/water HP; air/air HP; } \\
\text { PV; EV }\end{array}$ \\
\hline L15 & New & $\begin{array}{l}M(55-64) \\
F(55-64)\end{array}$ & - & $\begin{array}{l}\text { Retired } \\
\text { Early retirement }\end{array}$ & $\begin{array}{l}\text { College } \\
\text { College }\end{array}$ & $\begin{array}{l}\text { Hybrid Air/water HP with } \\
\text { gas boiler; PV; EV }\end{array}$ \\
\hline P3 & New & $\begin{array}{l}M(35-44) \\
F(35-44)\end{array}$ & $\begin{array}{l}F(10-14) \\
M(10-14) \\
M(10-14)\end{array}$ & $\begin{array}{l}\text { Wage earner } \\
\text { Wage earner }\end{array}$ & $\begin{array}{l}\text { College } \\
\text { Lower secondary school }\end{array}$ & $\begin{array}{l}\text { Hybrid Air/water HP with } \\
\text { gas boiler. PV; EV }\end{array}$ \\
\hline F7 & New & $\begin{array}{l}\mathrm{M}(45-54) \\
F(45-54)\end{array}$ & - & $\begin{array}{l}\text { Wage earner } \\
\text { Self-employed }\end{array}$ & $\begin{array}{l}\text { College } \\
\text { University education }\end{array}$ & $\begin{array}{l}\text { Hybrid Air/water HP with } \\
\text { gas boiler. PV; EV }\end{array}$ \\
\hline S7 & New & $\begin{array}{l}M(25-34) \\
F(25-34)\end{array}$ & - & $\begin{array}{l}\text { Wage earner } \\
\text { Wage earner }\end{array}$ & $\begin{array}{l}\text { Vocational education } \\
\text { College }\end{array}$ & $\begin{array}{l}\text { Hybrid Air/water HP with } \\
\text { gas boiler; PV; EV }\end{array}$ \\
\hline
\end{tabular}

Post-print version, please cite this paper as: Hansen, M., \& Hauge, B. (2017). Energy Research \& Social Science Scripting, control, and privacy in domestic smart grid technologies: Insights from a Danish pilot study. Energy Research \& Social Science, 25, 112-123. http://doi.org/10.1016/j.erss.2017.01.005 


\begin{tabular}{|c|c|c|c|c|c|c|}
\hline L13 & New & $\begin{array}{l}M(45-54) \\
F(45-54)\end{array}$ & - & $\begin{array}{l}\text { Wage earner } \\
\text { Self-employed }\end{array}$ & $\begin{array}{l}\text { Vocational education } \\
\text { Vocational education }\end{array}$ & Air/water HP; PV; EV \\
\hline S4 & New & $\begin{array}{l}M(55-64) \\
F(55-64)\end{array}$ & - & $\begin{array}{l}\text { Wage earner } \\
\text { Wage earner }\end{array}$ & $\begin{array}{l}\text { Vocational education } \\
\text { Lower secondary school }\end{array}$ & Air/water HP; PV; EV \\
\hline S2 & New & $\begin{array}{l}M(35-44) \\
F(35-44)\end{array}$ & $\begin{array}{l}F(10-14) \\
M(10-14) \\
F(0-4)\end{array}$ & $\begin{array}{l}\text { Unemployed } \\
\text { Wage earner }\end{array}$ & $\begin{array}{l}\text { Vocational education } \\
\text { College }\end{array}$ & Sunwell; PV; EV \\
\hline$A 2$ & New & $\begin{array}{l}M(55-64) \\
F(55-64)\end{array}$ & - & $\begin{array}{l}\text { Early retirement } \\
\text { On sick leave }\end{array}$ & $\begin{array}{l}\text { Lower secondary school } \\
\text { Vocational education }\end{array}$ & Sunwell; PV; EV \\
\hline P5 & New & $\begin{array}{l}M(65+) \\
F(65+)\end{array}$ & - & $\begin{array}{l}\text { Retired } \\
\text { Retired } \\
\end{array}$ & $\begin{array}{l}\text { Vocational education } \\
\text { Lower secondary school }\end{array}$ & $\begin{array}{l}\text { Hybrid Air/water HP with } \\
\text { gas boiler; } 4 \text { kw PV; EV }\end{array}$ \\
\hline $\mathrm{H} 9$ & New & $\begin{array}{l}M(35-44) \\
F(45-54)\end{array}$ & $F(10-14)$ & $\begin{array}{l}\text { Wage earner } \\
\text { Wage earner }\end{array}$ & $\begin{array}{l}\text { University education } \\
\text { Bachelor }\end{array}$ & $\begin{array}{l}\text { Geothermal HP, solar } \\
\text { thermal collectors, PV; EV }\end{array}$ \\
\hline F15 & New & $\begin{array}{l}M(45-54) \\
F(45-54)\end{array}$ & $\begin{array}{l}M(15-19) \\
F(10-14)\end{array}$ & $\begin{array}{l}\text { On sick leave } \\
\text { Self-employed }\end{array}$ & $\begin{array}{l}\text { Lower secondary school } \\
\text { Lower secondary school }\end{array}$ & $\begin{array}{l}\text { Hybrid HP with gas boiler; } \\
\text { PV; EV }\end{array}$ \\
\hline D22 & New & $\begin{array}{l}\mathrm{M}(35-44) \\
\mathrm{F}(35-44)\end{array}$ & - & $\begin{array}{l}\text { Wage earner } \\
\text { Wage earner }\end{array}$ & $\begin{array}{l}\text { College } \\
\text { College }\end{array}$ & Geothermal HP; PV; EV \\
\hline Ba3x & New & $\begin{array}{l}M(35-44) \\
F(25-34)\end{array}$ & - & $\begin{array}{l}\text { Wage earner } \\
\text { Wage earner }\end{array}$ & $\begin{array}{l}\text { Vocational education } \\
\text { College }\end{array}$ & Air/water HP, PV; EV \\
\hline
\end{tabular}

Information about participants: * PVs in Denmark became especially favourable after the 'solar agreement' in 2012, which included a lucrative deal for prosumers, in which they were paid by the state for delivering electricity to the grid. The 'Netto-måler-ordningen' (net-meter-scheme) agreement, which is referred to as 'the old agreement,' included the yearly settlement of accounts regarding the produced electricity and the stipulation that the capacity not exceed $6 \mathrm{~kW} /$ household. Due to this lucrative deal and the decline in prices of PV panels, many households purchased PVs, which caused a massive loss for the state. Thus, a new agreement named 'Net-metre-by the hour' ('Time-netto-ordningen'), referred to as the 'new agreement,' was constructed. It includes a different set-up for the prosumer. With this new agreement, a maximum surplus of electricity from the solar panels of $6 \mathrm{~kW}$ was sold at the fixed price of $0.6 \mathrm{DKK} / \mathrm{kWh}$ for PVs installed after September 19, 2012 (http://www.energinet.dk/DA/El/Solceller/Har-du-

solceller/Sider/Nettoafregningsgrupper.aspx). Because the amount of electricity is accounted for each hour, the surplus of electricity is sold at a price of $0.6 \mathrm{DKK} / \mathrm{kWh}$, which increased to a price of $2.20 \mathrm{DKK} / \mathrm{kWh}$ in the evening.

iv A sociologist employed by Insero Business Services had the tasks of primary communication with households and the evaluation of household installations. The authors of this paper collected data in Insero Live Lab. As researchers, the authors were allowed to use Insero Live Lab as a case study, which also increased the amount of acquired knowledge about the participating households from Insero's perspective. Thus, the authors did not participate in the shaping of the project, but they chose the data collection methods.

${ }^{\vee}$ Before the interviews, an interview guide that addressed the following areas was prepared: total use of the house (residents and their practices related to the home), digital behaviours, energy technologies, and car usage/practices. These themes were important to gain knowledge about the informants and their relation to both relevant technologies and energy use. This interview round was also important to inform participants of their roles in the trial and to create an initial connection between the informants and Insero employees.

${ }^{\mathrm{vi}}$ Both the husband and wife were interviewed, although this was not possible in a few cases.

vii The audio recordings of the four interviews conducted with two eButler software designers and two Insero employees were lost. Therefore, they could not be transcribed and coded.

viii Surveillance has long been described as a method for taking social control, disempowering people, and providing a panoptic viewpoint as an institutional way of gaining power (Foucault, 1977). However, some CCTV studies reveal a more subtle nature of the relationship between the watcher and the watched. In this paper, the technologies of control have been defined as "social mediums facilitating interaction and socialization, the watched being both objects of information and subjects of communication, the watchers assuming the role of a pseudo-tv audience trying to make sense of a reality Soap Opera which is both enlightening and imprisoning" (Smith, 2007: 309). Another study illustrates that although surveillance systems can be "designed to identify and to singularize the exceptional, the non-normative" (Rapport, 2012, in Mäkinen, 2016: 74), the actual usages of domestic surveillance systems were substantially more diverse and reflected a mix of conflicting issues (protecting one's property vs subjecting oneself to monitoring; feeling safe vs feeling exposed; and communicating with loved ones vs being suspected of spying on them.

Post-print version, please cite this paper as: Hansen, M., \& Hauge, B. (2017). Energy Research \& Social Science Scripting, control, and privacy in domestic smart grid technologies: Insights from a Danish pilot study. Energy Research \& Social Science, 25, 112-123. http://doi.org/10.1016/j.erss.2017.01.005 
(Mäkinen, 2016). Many similar contradictions appeared in remote control situations, which indicates that the logic and the script that underpin the smart grid system entails control for the sake of energy care and data. Common uses of these systems involve ambivalent feelings about the systems.

ix eButler was developed for utility companies and was intended as a platform to facilitate communication between the utilities and their customers. The program needed to be changed to fit Insero Live Lab. Thus, some functional limitations were initially encountered; some of these limitations were improved during the process.

${ }^{\times}$Each participant would receive a subsidy of approximately 50\% of the price of the PV and the HP. The EV and charging station are leased for two years.

${ }^{x i}$ The control of the air/water HPs was based on 'Control Your Heat pump' ("StyrDinVarmepumpe",2015), a tested platform that can be used to externally control HPs. The project was based on a pilot project in which $300 \mathrm{HPs}$ have already been remotely controlled to investigate the potential of HPs in relation to flexibility (Intelligent Energistyring AmbA et al. 2015). This study was also the reason for the choice of the particular brands in the initial package.

xii This paper does not include an investigation of the efficiency of solar wells (or other technologies) because this issue is beyond the defined scope.

xiii Other studies have focused on visualization and feedback. Some studies have critically assessed the role of energy feedback in reducing households' consumption (Van Dam, Bakker, \& Buiter, 2013; Hargreaves, Nye, \& Burgess, 2013). Energy feedback has also been shown to have an empowering effect on the residents in some cases (Buchanan, Russo, and Anderson 2014).

${ }^{x i v}$ For a detailed description of the practices, refer to Hansen \& Hauge, 2016.

${ }^{x v}$ We include all equipment that informed participants of their energy consumption or visualised energy consumption and production in this term.

xvi Refer to note vi for a description of the new/old billing accounts.

xvii Coefficient of Performance.

xviii The fact that the price for delivering electricity to the grid was low gave the participants incentives to use all produced electricity within the hour to receive approximately 2 DKK instead of 0.6 DKK for each kWh.

Post-print version, please cite this paper as: Hansen, M., \& Hauge, B. (2017). Energy Research \& Social Science Scripting, control, and privacy in domestic smart grid technologies: Insights from a Danish pilot study. Energy Research \& Social Science, 25, 112-123. http://doi.org/10.1016/j.erss.2017.01.005 